\title{
Embedded Intelligent Structures for Energy Management in Vehicles
}

\author{
Ana Puşcaş ${ }^{1}$, Marius Carp ${ }^{1}$, Paul Borza ${ }^{1}$, and Iuliu Szekely ${ }^{2}$ \\ ${ }^{1}$ Transilvania University of Braşov, Electrical Engineering and Computer Science \\ 29 Eroilor Street, 500036, Braşov, Romania \\ ${ }^{2}$ Acta Universitatis Sapientiae, \\ 1 Sighisoarei Street, 540485, Targu Mureş, România \\ \{ana_maria.puscas,marius.carp\}@yahoo.com, paul.borza@unitbv.ro, \\ gszekely@ms.sapientia.ro
}

\begin{abstract}
The present research is focused on developing embedded intelligent structures for energy management in mobile systems. The research introduces a hybrid structure composed of different energy sources endowed with control systems able to optimize the power flow of the ensemble. In the paper, the architecture of the proposed hybrid system is described. To test the functionality and the advantages of the system, preliminary simulations were made. To characterize the behaviour of the physical developed system, a test bench was implemented.
\end{abstract}

Keywords: combined energy sources, energy efficiency, control systems, control strategies, electric vehicle.

\section{Introduction}

Lately, the automotive industry has been focused on reducing fuel consumption, energy consumption and pollutant emissions while increasing the global efficiency of the vehicle and the passengers' comfort. The new facilities for improving the comfort (HVAC system of the vehicle, GPS, night vision camera, parking assistant etc) increase the energy and fuel consumption, thus heating the battery, reducing its lifetime and performances and affecting the environment.

In order to respect environmental issues, the general trend in the automotive industry is to transit from the classic vehicles toward hybrid electric vehicles (HEV) and electric vehicles (EV), non-polluting and economical vehicles [1].

Starting 1997, Toyota and Honda opened the gates in HEV and EV. At present, efforts are being made for the transition to pure EV (battery EV and fuel cell EV). In this sense, both Honda and Toyota companies have developed models certified by the U.S. Environmental Protection Agency (EPA) and California Air Resources Board (CARB) as being Partial Zero Emission Vehicle (PZEV) and ZEV.

The final aim of the present research is to optimize the energy and fuel consumption of the $\mathrm{HEV} / \mathrm{EV}$, the lifetime of the storage devices and to increase energy efficiency. As a result, the autonomy and the dynamism of the vehicles have to be increased. In order to fulfil the final aim, the goal of the paper is to study and optimize 
the power flow between the electrical and mechanical sides of an EV. By considering a combined energy cell (CEC), DC-DC converter, electrical machine (DC motor/generator - MG) and flywheel that simulates the inertia of the EV, a reduced scale model was developed before a detailed analysis of the components was performed. A CEC represents a hybrid system composed of different storage and generation devices with different time constants (battery, supercapacitor - SC), all embedded in an intelligent structure with computation abilities.

Starting from a theoretical approach, a model of a network of four CEC cells was simulated. Based on the results of the simulations, a first image about the implementation was achieved. In the experimental phase, a test bench for a reduced scale physical model that includes one CEC was designed and implemented. Also, an embedded intelligent structure for energy management (EISEM) was developed. To facilitate the energy management process of an EV, the EISEM integrates energy storage devices and use embedded systems based on microcontrollers (UC) and network of switching devices. Using the prototype, the regenerative braking process of the EV was simulated, the experimental results being emphasized in the paper.

\section{Contribution to Sustainability}

Nowadays, the increase in energy efficiency represents the main target of any emergent technology. In the present research, an innovative technique that reflects the fusion between energy and information implemented as a dynamic network of CEC cells is proposed. The sustainability targets are related to improving the performances of the three level cellular power supply architecture and of the control strategies (laws) that govern it. For the CEC structure (first level), a simple control strategy was considered and implemented. At the network level (second level), the dynamic changing of the topology was simulated. At the vehicle level (third level), the corollary of the research will be achieved by correlating the transport missions with the energy resources of the vehicle.

Using EISEM devices, an optimal balance between the provided power and the energy density is reached. Also, the volume, the wasted energy and the pollution are reduced, such a system being suitable for Start/Stop systems and regenerative braking processes. Based on the experimental and simulation results, the performances of the EISEM are evaluated and its model will be integrated as power supply in the overall HEV/EV models. Considering the economical aspects, this solution represents a good compromise between performances and the costs obtained without major technological efforts. Thus, the prototype is considered an important step toward improving the sustainability of the energetic solutions.

\section{Storage Devices Used in Automotive - State of the Art}

The development of the HEV/EV is limited especially because of their power supplies and their weak characteristics. Even in the case of NiMH and Li-ion batteries this limitation persists and affects the reliability and the autonomy of the vehicle [2]. The energy efficiency, lifetime, cyclability, dynamical performances and the starting processes are affected by the functioning regimes of the vehicles [3]. In addition, the high 
time constant of the battery decreases the performances of the regenerative braking process thus limiting the technological advance in the energy management systems for $\mathrm{HEV} / \mathrm{EV}$.

The actual solutions overpassing the above mentioned issues consist in: (i) increasing the vehicle's voltage from $12 \mathrm{~V}$ to $42 \mathrm{~V}$; (ii) oversizing the battery's capacity; (iii) hybridization of the power supply and increasing the dynamicity of the vehicles in urban traffic by including fast release storage devices. The disadvantage of the first solution is related to the high costs of the vehicles' technology translation. The disadvantages of the second solution are related to increasing the costs, the carried weight of the system and the pollution. The third solution represents the actual trend in automotive, an optimal and sustainable compromise [4], [5], [6], [7], [8], [9].

Because there is no device able to ensure high energy and power densities, and increased lifetime at the same time, the automotive industry has focused its attention on developing embedded control solutions for reducing fuel consumption and increasing efficiency [10], [11], [12]. The actual research uses batteries as storage devices but there are also implementations which use SC in order to increase the power density and the lifetime of the ensemble [3], [13], [14], [15].

The present paper describes a hybrid storage and energy device embedded in an intelligent structure. The hybrid system is composed of cells of batteries, SC, sensor networks and intelligent control system able to combine and commute all the storage and generation devices thus optimizing the power flow. The SC has the advantage of being non-polluting and able to provide and smooth high peak current pulses, thus increasing the lifetime of the battery [16]. The main difference between the researched system and the existing ones is the control made at cell level, instead of the control made at device level [17].

\section{Hybrid Storage Device - Architecture}

By connecting multiple storage devices (batteries, SC, flywheels) characterized by different time constants and performances into embedded intelligent structures, with a view to ensuring long lifetime, high energy density, and high power density of the ensemble, storage and energy device hybridization is obtained (Fig. 1) [18]. For increasing the performances of the ensemble, the hybrid system was endowed with an intelligent control system able to monitor, control and optimize the energy flow of the vehicle, thus improving its performances. The architecture of the hybrid structure, illustrated in Fig. 2, is composed of EISEM connected to a MG controlled though PWM. The EISEM consists of: (i) CEC: hybrid device composed of cells of storage devices and back to back switches able to ensure the bidirectional power flow (Fig. 1); (ii) Data Acquisition System (DAQ): embedded system based on ATMega128 UC used for acquiring data from the voltage, current and revolution sensors; (iii) Control System: embedded system based on UC for controlling and optimizing the power flow transferred through CEC.

Multiple EISEM can be connected in series/parallel to increase the performances of the system (Fig. 3). 


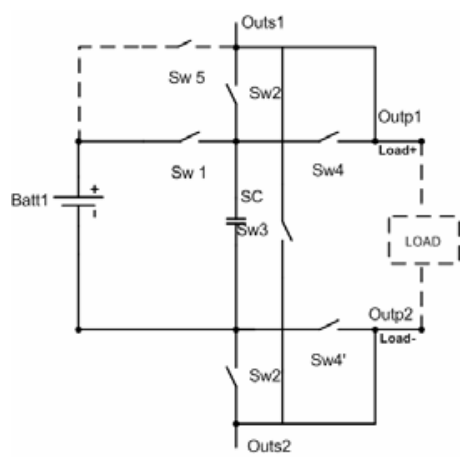

Fig. 1. CEC cell

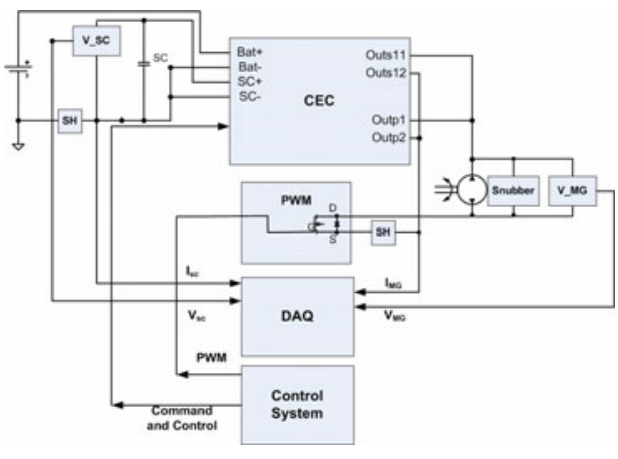

Fig. 2. Architecture of the hybrid structure

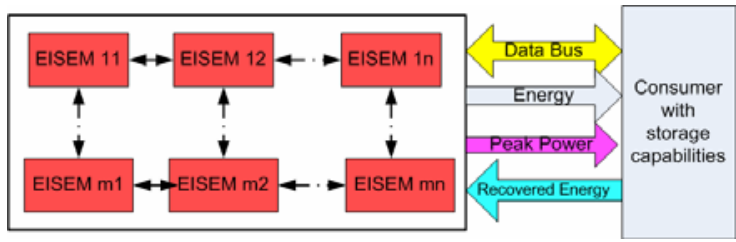

Fig. 3. Network of EISEM

\section{Simulations and Results}

The main advantages of a hybrid storage device are related to: (i) increasing the lifetime of the battery by supplying the high peak pulses from the SC in the starting process and (ii) improving the energy efficiency of the system in the regenerative braking process because of the reduced time constants of the SC [19].

To highlight the performances and the advantages of a network of CEC cells (Fig. 3), the system was modelled and simulated with Matlab/Simulink tool. The architecture of the modelled system is illustrated in Fig. 4. The simulated network was composed of four CEC cells which can be connected in series and/or in parallel in order to ensure the load profile. In the simulated hybrid device composed of four CEC cells, four $400 \mathrm{~F} / 42 \mathrm{~V} \mathrm{SC}$ and four $77 \mathrm{Ah} / 42 \mathrm{~V}$ lead acid batteries were used. Also, as analogy with the inertial storage from HEV/EV, two capacitive loads $($ Loadl $=400 \mathrm{~F}$, Load2 $=200 \mathrm{~F}$ ) were considered.

The control strategy (Fig. 5) was implemented to charge the Loadl from $0 \mathrm{~V}$ to $40 \mathrm{~V}$ and to supply Load2 from Load1. To control the charging process, voltage transducers were used.

The results of the simulations are illustrated in Fig. 6 a), b).

The results of the simulations are in accordance with the logic described by the control algorithm (Fig. 5). Depending on the voltage of the load, the network of cells was commuted. In State1, Load1 is charged from SC-CEC1 until its voltage reaches $10 \mathrm{~V}$. In State2, Load1 was charged up to $20 \mathrm{~V}$ from the SC-CEC2, in State3, Load1 was charged up to $30 \mathrm{~V}$ from the SC-CEC3. From State4 started the stabilization 


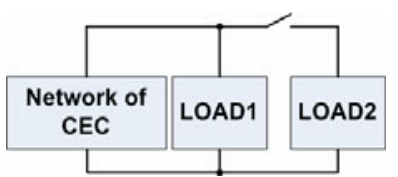

Fig. 4. Simulated system

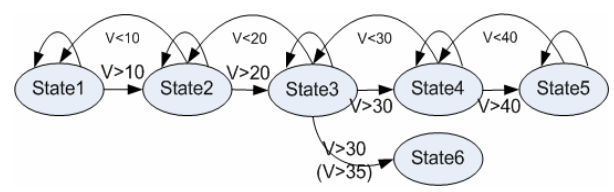

Fig. 5. Control strategy used in simulations

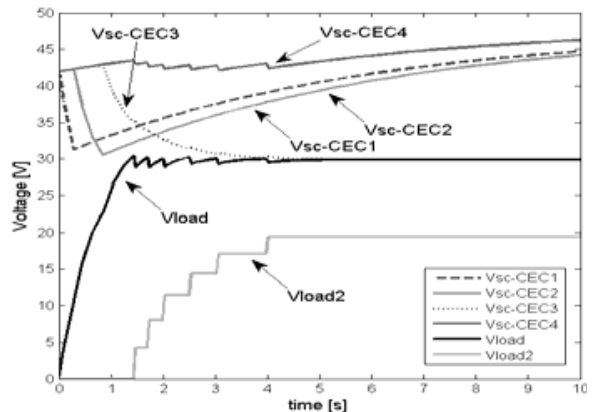

(a)

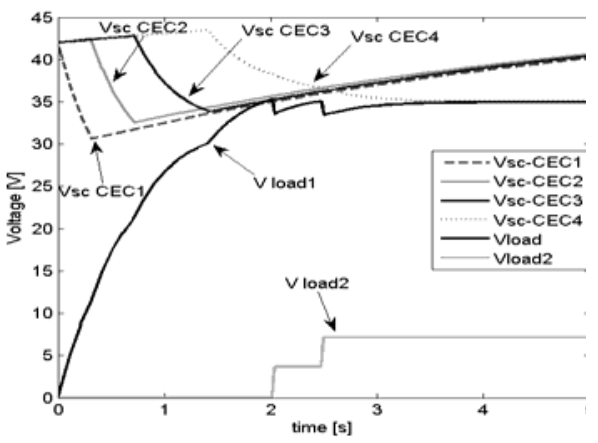

(b)

Fig. 6. Results of the simulation

phase; the algorithm jumped in State5 and State6 in order to supply Load2 while maintaining the voltage on Load1. Thus, for voltages measured on Load1 greater than $30 \mathrm{~V}$ (Fig. 6 a) and $35 \mathrm{~V}$ (Fig. 6 b), Load2 was supplied from Load1. At the same time, the CEC cells were used for maintaining the $30 \mathrm{~V}$ (respectively $35 \mathrm{~V}$ ) level on Load1. The simulations proved that a network of CEC hybrid devices endowed with the adequate control strategies can be used for mastering the desired load profile. This embedded system reflects the fusion between the power flow transmitted bidirectionally between generator - load and the necessary information for the control strategies.

\section{Experiments and Results}

A single EISEM cell was implemented and tested before the physical implementation of the network of cells. In order to experimentally test the functionality of the prototype (EISEM hybrid device) (Fig. 2) and its efficiency, a first test bench was implemented. The test bench (Fig. 7) is composed of: Device Under Test (DUT), DAQ, Control System and laptop.

The DUT module consists of: CEC hybrid system, $120 \mathrm{~W} \mathrm{MG}$ with $0.27 \mathrm{~kg} / \mathrm{m}^{2}$ inertia, snubber circuit, Hall sensors for monitoring the values of the MG and SC currents, sensors for monitoring the MG and SC voltages and optical sensors for monitoring the revolution of the MG. A $0.11 \mathrm{~F}$ small $\mathrm{SC}$ was used as generation and storage device in CEC. The battery was simulated with a DC voltage source limited at $2.5 \mathrm{~A}$ and $5 \mathrm{~A}$. 


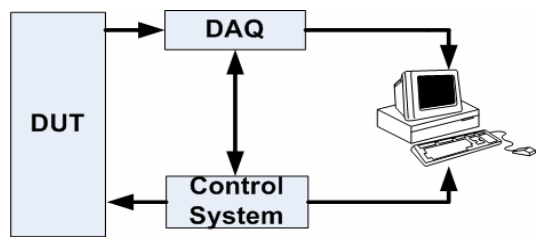

Fig. 7. Test Bench

The system was implemented to ensure the communication between the modules. Data were acquired with DAQ, were sent to a laptop by using Visual Basic software and UART facilities and were locally stored and processed using Matlab tool. Based on the information received from DAQ, the Control System interprets the data and controls both modules DAQ and CEC in order to optimize the process.

The first experiments were made while supplying the $\mathrm{MG}$ at the power values of $12.5 \mathrm{~W}$ (Fig. 8) and $40 \mathrm{~W}$ (Fig. 9). In these experiments, while braking, the energy is recovered and stored on the SC without using a DC-DC converter.

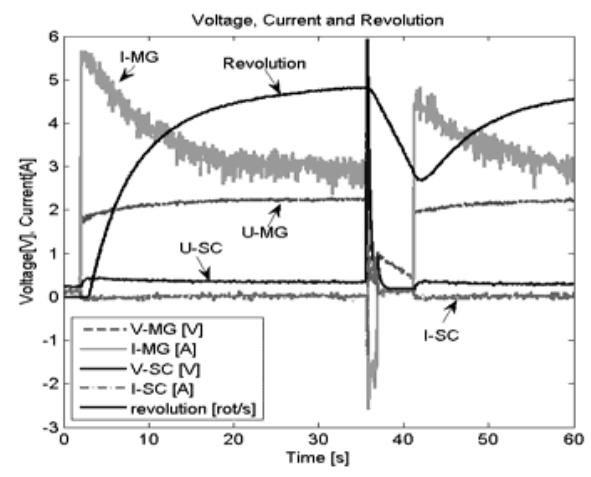

Fig. 8. Experiments at $2.5 \mathrm{~V}$ and $5 \mathrm{~A}$

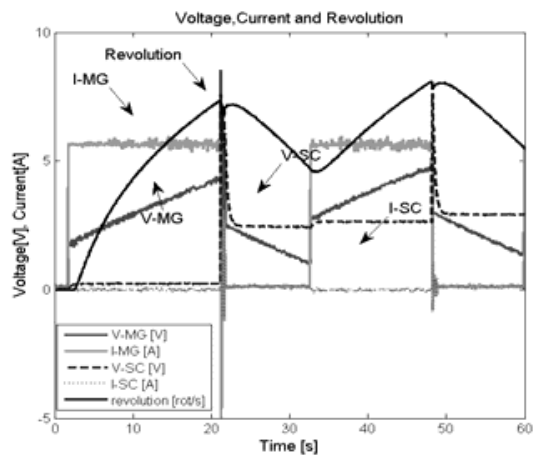

Fig. 9. Experiments at $8 \mathrm{~V}$ and $5 \mathrm{~A}$

If a DC-DC converter and adequate control system are integrated in the tested prototype, the recovered energy can be significantly increased (Fig. 10 and Fig. 11).

In the experiments, the regenerative braking efficiency implemented at reduced scale was tested. The energy recovered and available in the SC is given by Eq. 1:

$$
E=(1 / 2) \cdot C \cdot\left(U_{\max }^{2}-U_{\min }{ }^{2}\right) .
$$

By analogy with the urban traffic, a control strategy was conceived. The strategy controls the modality to provide the energy necessary to move the vehicle by accelerating and to recuperate the energy by decelerating. As it can be seen in Fig. 10 and Fig. 11 the energy recovered in 60 seconds of successive accelerations and breakings, while the MG is supplied at $2.5 \mathrm{~V} / 2.5 \mathrm{~A}$ is $0.22 \mathrm{~J}$ and while the $\mathrm{MG}$ is supplied at $8 \mathrm{~V} / 5 \mathrm{~A}$ is $1.48 \mathrm{~J}$. Thus, if supplying at $12 \mathrm{~V} / 5 \mathrm{~A}$ the energy recovered in 60 seconds is $8 \mathrm{~J}$. For testing a real implementation of regenerative braking on EV, $400 \mathrm{~F} / 14 \mathrm{~V}$ 
SC able to recover $39.2 \mathrm{~kJ}$ will be used. Thus, the energy efficiency can be significantly increased by recovering the energy usually lost into heat.

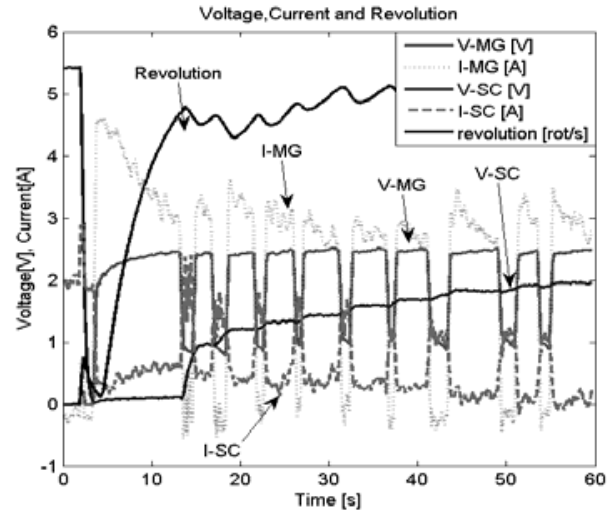

Fig. 10. Experiments at $2.5 \mathrm{~V}$ and $5 \mathrm{~A}$

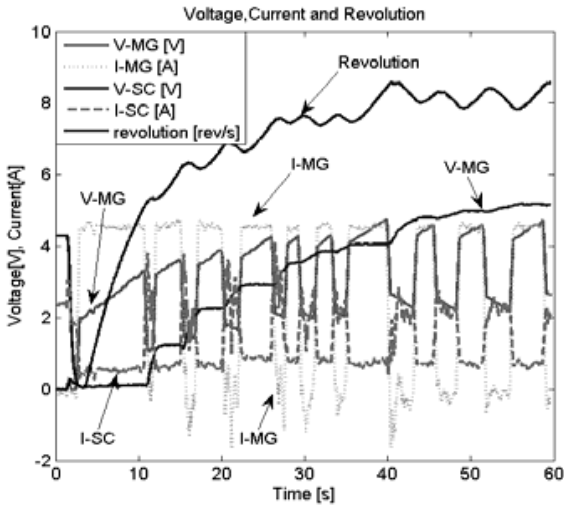

Fig. 11. Experiments at $8 \mathrm{~V}$ and $5 \mathrm{~A}$

\section{Conclusions and Future Work}

This paper briefly presents the advantages of using embedded intelligent structures for increasing the performances of the HEV/EV. The paper demonstrates the viability of a cellular concept used for controlling the power flow from the sources toward loads with storage characteristics, as an alternative to the batteries systems endowed with DC-DC converters. By analogy, this application is similar to the generic control of the $\mathrm{HEV} / \mathrm{EV}$ where an essential phenomenon consists in recuperating the kinetic energy of the vehicle. The energy efficiency can be increased by replacing the DC-DC converters with such network of CEC cells.

In the present paper, a network of EISEM was introduced and the EISEM hybrid energy storage device was detailed. To observe its behaviour, the EISEM composed of four CEC cells was firstly modelled and simulated. The simulations proved that the EISEM not only can increase the performances of the ensemble, but it also can be endowed with an adequate control system in order to optimize and maintain the load profile.

A first reduced scale physical prototype of the EISEM hybrid configuration was implemented and its architecture was described. The experimental results proved its efficiency while using it in the regenerative breaking and starting processes. Based on the experiments, the corresponding model has to be developed and simulated.

As future work, the network of EISEM cells will be physically implemented. Inside the network, the EISEM cells will have the capability to communicate with a control system and also between them. The control system will have the intelligence to optimally connect the EISEM cells in order to optimize the power flow inside the system. Also, a full scale implementation for EV and HEV has to be done. 
Acknowledgments. This paper is supported by the Sectoral Operational Programme Human Resources Development (SOP HRD), financed from the European Social Fund and by the Romanian Government under the contract number POSDRU/6/1.5/S/6.

\section{References}

1. Larminie, J., Lowry, J.: Electric Vehicle Technology Explained. John Wiley, Chichester (2003)

2. Settle, F.A. (ed.): Handbook of Instrumental Techniques for Analytical Chemistry. Prentice-Hall, Inc., NJ (1997)

3. Borza, P., Puşcaş, A.M., Szekely, I., Nicolae, G.: Energy Management System based on supercapacitors used for starting of internal combustion engines of LDH1250 locomotives and charging their batteries. In: SIITME 2008, Predeal, România, pp. 227-231 (2008)

4. Karden, E., Ploumen, S., Fricke, B., Miller, T., Snyder, K.: Energy storage devices for future hybrid electric vehicles. Journal of Power Sources 168, 2-11 (2007)

5. Dobner, D.J., Woods, E.J.: An Electric Vehicle Dynamic Simulation. GM Research Laboratories, pp. 103-115 (1982)

6. Salameh, Z.M., Margaret, A.C., Lynch, W.A.: A Mathematical Model for Lead-Acid Batteries. IEEE Transactions on Energy Conversions 7(1), 93-97 (1992)

7. Appelbaum, J., Weiss, R.: Estimation of Battery Charge in Photovoltaic Systems. In: 16th IEEE Photovoltaic Specialists Conference, pp. 513-518 (1982)

8. Baudry, P.: Electro-thermal modelling of polymer lithium batteries for starting period and pulse power. Journal of Power Sources 54, 393-396 (1995)

9. Guerrero, M.A., et al.: Overview of Medium Scale Energy Storage Systems. Compatibility and Power Electronics 6 (2009)

10. Fuhs, A.E.: Hybrid vehicles and the Future of Personal Transportation. CRC Press, Boca Raton (2009)

11. Carp, M.C., et al.: Monitoring system and intelligent control system used in the starting process of a LDH1250HP locomotive. In: 12th OPTIM 2010, pp. 551-556 (2010)

12. Mitsubishi Electric Shows Prototypes of Ultracapacitor-Battery Hybrid Energy Storage Device (2010), http: / / www . greencarcongress . com

13. Ayad, M.Y., Rael, S., Davat, B.: Hybrid power source using supercapacitors and batteries. In: Proc. IEEE-PESC 2003, Acapulco (2003)

14. Cericola, D., et al.: Simulation of a supercapacitor/Li-ion battery hybrid for pulsed applications. Journal of Power Sources 195, 2731-2736 (2010)

15. Kötz, R., Carlen, M.: Electrochimica Acta 45, 2483-2498 (2000)

16. Conway, B.E.: Electrochemical supercapacitors - scientific fundamentals and technological applications. Kluwer Academic/Plenum Publishers (1999)

17. Borza, P.: Electric Power Cell. Patent EP 1796199 (2007)

18. Brice, L., Magali, L.: Automatic vehicle start/stop control method. US Patent 2009/0216430 A1, Dayton, OH US (2009)

19. Puscas, A.M., et al.: Thermal and Voltage Testing and Characterization of Supercapacitors and Batteries. In: OPTIM 12th 2010, Brasov, pp. 125-132 (2010) 